\title{
Cardiac dysfunction in type II diabetes: a bittersweet, weighty problem, or both?
}

\author{
Melissa Leung ${ }^{1,2,3}$ (1) Vincent W. Wong ${ }^{2,4} \cdot$ Ertugrul Durmush $^{5}$ - Victoria Phan ${ }^{1,2}$. \\ Mikey Xie ${ }^{1,2} \cdot$ Dominic Y. Leung ${ }^{1,2}$
}

Received: 23 June 2016/Accepted: 1 September 2016/Published online: 1 October 2016

(c) The Author(s) 2016. This article is published with open access at Springerlink.com

\begin{abstract}
Aims Weight loss in obese patients leads to improved left ventricular $(\mathrm{LV})$ function. It is unclear whether improving glycaemic control has additional benefits to weight loss alone in patients with type 2 diabetes, or if benefits of weight loss are mediated through improving glycaemic control. This case-control study examined the incremental impact of these approaches on LV function.

Methods Three groups of age, gender, and baseline HbA1c-matched patients with type 2 diabetes and suboptimal glycaemic control were followed-up for 12 months. Group 1 patients did not improve $\mathrm{HbA1c} \geq 1 \%$ $(10.9 \mathrm{mmol} / \mathrm{mol})$ or lose weight. Group 2 improved HbAlc $\geq 1 \%$ but did not lose weight. Group 3 improved $\mathrm{HbA} 1 \mathrm{c} \geq 1 \% \quad(10.9 \mathrm{mmol} / \mathrm{mol})$ and lost weight. All patients underwent transthoracic echocardiogram at baseline and at follow-up.
\end{abstract}

Managed by Antonio Secchi.

Melissa Leung

melissa@unsw.edu.au

1 Department of Cardiology, Liverpool Hospital, South Western Sydney Clinical School, University of New South Wales, Locked Bag 7103, Liverpool BC, NSW 1871, Australia

2 Ingham Institute for Applied Medical Research, Sydney, NSW, Australia

3 Leiden University Medical Centre, Leiden, The Netherlands

4 Liverpool Diabetes Collaborative Research Unit, South Western Sydney Clinical School, University of New South Wales, Locked Bag 7103, Liverpool BC, NSW 1871, Australia

5 The Life Weight Loss Centre, Liverpool, NSW, Australia
Results At baseline, three groups were comparable in all clinical and metabolic parameters except Group 3 had highest body mass index. The three groups had similar echocardiographic parameters except Group 3 had the worst LV systolic function [global longitudinal strain (GLS)]. At follow-up, LV ejection fraction and diastolic function improved with a reduction in filling pressures in Group 2 and more so in Group 3. LV filling pressures in Group 1 increased. There was a significant improvement in GLS in Group 2 and more so in Group 3. Despite GLS being the worst in Group 3 at baseline, this was comparable between Groups 2 and 3 at follow-up.

Conclusions In overweight patients with type 2 diabetes, weight loss and improved glycaemic control had additive beneficial effects on improving LV systolic and diastolic function.

Keywords Diabetic cardiomyopathy - Glycaemic control . Left ventricular function - Echocardiography - Strain .

Weight loss · Bariatric surgery

\section{Introduction}

Patients with type 2 diabetes are often overweight and have multiple vascular risk factors. This may manifest as left ventricular (LV) systolic and/or diastolic dysfunction, or blunted heart rate variability, not attributable to hypertension or myocardial ischaemia [1-5]. The underlying pathophysiologic mechanisms of LV dysfunction in these patients are multifactorial, but hyperglycaemia is considered a main determinant [6, 7]. However, the relationship between glycaemic control and cardiac function has been conflicting with some studies showing poor glycaemic control was associated with abnormal LV relaxation, 
elevated LV filling pressures, and lower systolic strain $[2,8,9]$, while other studies demonstrated no such significant association [10-14]. Furthermore, studies examining the relationship between glycaemic lowering and LV function also gave inconsistent results [15-18].

Echocardiographic strain imaging and tissue Doppler velocities are proven techniques in the assessment of $\mathrm{LV}$ systolic and diastolic function that have incremental prognostic value to traditional echocardiographic parameters like LV ejection fraction [19-22]. Echocardiographybased calibrated integrated backscatter (cIB), shown to be related to histologically quantified collagen accumulation, may be used as a measure of myocardial interstitial fibrosis $[23,24]$.

Obesity alone, in the absence of diabetes, has also been linked to LV dysfunction, and weight loss in obese patients has been shown to result in improved LV function [25]. To date, studies examining the relationship between glycaemic lowering and LV function in patients with type 2 diabetes have not clarified the differential impact of weight loss and improved glycaemic control in overweight patients with type 2 diabetes. It is unclear whether weight loss has incremental benefits to improved glycaemic control in these patients or indeed whether the benefits of weight loss in obese patients with type 2 diabetes are mediated through improved glycaemic control only. This case control study was conducted to examine the differential and incremental benefits of weight loss and improved glycaemic control on LV function in obese patients with type 2 diabetes.

\section{Subjects, materials, and methods}

\section{Patients}

The study patients were recruited from a cardio-diabetology clinic where patients with poorly controlled type 2 diabetes were referred and jointly managed by an endocrinologist and a cardiologist. Eligible patients included adults with type 2 diabetes with suboptimal glycaemic control (glycated haemoglobin [HbA1c] $\mathrm{HbA} 1 \mathrm{c} \geq 7.0 \%, 53 \mathrm{mmol} / \mathrm{mol})$. Patients with type 1 diabetes, known congenital, valvular, or coronary artery disease (CAD), severe hypertension $(>200 / 120 \mathrm{mmHg}$ at rest), left bundle branch block, rhythm other than sinus, previous or current treatment with thiazolidinediones, and previous history of hypoglycaemia unawareness, were excluded. All patients had significant CAD excluded by exercise echocardiography when they first attended the clinic. Their glycaemic control, blood pressure, and lipid profile were optimized, and they were reviewed 3 monthly for 12 months after which time the patients were discharged back to their primary care physicians. Patients were advised to follow a diet of low glycaemic index and to reduce excessive carbohydrate and fat intake. Overweight or obese patients were recommended a healthy balanced diet but aimed at reduced energy intake and referred for individual dietitian consultation when necessary. Ten patients elected to undergo bariatric surgery of their own volition and were deemed suitable by a bariatric surgeon for laparoscopic sleeve gastrectomy. These patients undertook a pre-operative very low calorie diet in combination with a 3-week exercise programme supervised by an exercise physiologist, a dietician, and a psychologist; following which surgery was performed. All subjects had normal resting electrocardiogram and provided written informed consent. The study was approved by the Hospital Human Ethics Committee.

A group of 20 patients ("Group 1") who failed to improve (or had worsened) their glycaemic control and did not lose any weight after 12 months was identified. Failure to improve glycaemic control was defined as an improvement of $\mathrm{HbA} 1 \mathrm{c}$ of $\leq 1 \%(10.9 \mathrm{mmol} / \mathrm{mol})$ or any increase in HbAlc after 12 months. A second group ("Group 2") of 20 age-, gender-, and baseline HbAlcmatched patients who improved their glycaemic control but did not lose any weight in the 12-month period was selected. The third group ("Group 3") of ten similarly matched patients at study entry comprised those patients who underwent sleeve gastrectomy, improved their glycaemic control [defined as a decrease of HbAlc $>1 \%$ $(10.9 \mathrm{mmol} / \mathrm{mol})$ at 12 months] and who had lost weight over the 12-month period. Therefore, the total study population comprised of 50 patients.

\section{Baseline clinical and metabolic data}

Clinical data collected at baseline included age, height, weight, waist and hip circumference, cardiac risk factors, duration of diabetes, medications, and presence of macrovascular and microvascular complications. All subjects ranked their degree of breathlessness from 1 to 5 using the Medical Research Council (MRC) dyspnea scale [26]. Those ranked scale 1 had minimal dyspnea except on strenuous exercise, while those in scale 5 were too breathlessness to perform simple tasks such as undressing.

Patients' haemoglobin, HbAlc, serum creatinine, estimated glomerular filtration rate (eGFR) using the Chronic Kidney Disease Epidemiology Collaboration (CKD-EPI) formula [27], fasting total cholesterol, low-density lipoprotein cholesterol (LDL-C), high-density lipoprotein cholesterol (HDL-C), and triglycerides, C-reactive protein (CRP), and urinary spot albumin-to-creatinine ratio were measured at baseline and 12 months. 


\section{Follow-up}

All patients were reviewed 3 monthly at the clinic and had their medical treatment for diabetes, blood pressure, and cholesterol levels optimized aiming to achieve guidelinerecommended targets. Treatment was maintained and monitored for 12 months.

\section{Echocardiography protocols}

All patients underwent rest echocardiography followed by symptom-limited exercise echocardiography at baseline. A repeat echocardiogram was performed at 12 months.

\section{Two-dimensional and Doppler echocardiography}

All transthoracic echocardiograms were performed with Vivid E9, GE Medical Systems. All standard echo and Doppler parameters of LV systolic and diastolic function including pulse wave tissue Doppler were measured.

\section{Left ventricular strain imaging}

Global mean peak longitudinal strain (GLS) and strain rate of the left ventricle was obtained with two-dimensional speckle tracking analyses in apical 4-, 2-chamber and long-axis views using highest possible frame rates. Analyses were performed by experienced observers blinded to the clinical history and metabolic profiles. The GLS and strain rate were calculated from the three global longitudinal strain curves of the three apical views. All Doppler and 2D speckle tracking echocardiographic measurements were taken as averages of three representative cycles.

\section{Left atrial volume and function assessment}

Left atrial (LA) volumes were measured from the apical views according to the biplane Simpson's method. The following indices of LA function were measured: LA reservoir volume was calculated as the difference between the maximum and minimum LA volumes. Passive LA emptying volume was calculated as the difference between maximal and pre-contraction LA volumes. Active LA emptying volume was calculated as the difference between pre-contraction and minimum LA volumes. All LA volumes were indexed to body surface area.

\section{Calibrated integrated backscatter}

The cIB curves were extracted in the parasternal long-axis view, using standard software (Echopac, GE Vingmed). Measurements were obtained by placing a $8 \times 8 \mathrm{~mm}$ region of interest in the subendocardial basal anteroseptum, posterior wall, and pericardium at the peak of the R-wave on the ECG in the parasternal long-axis view. cIB was obtained by subtracting average pericardial backscatter intensity from average myocardial backscatter intensity of the anteroseptum or posterior wall.

\section{Statistical analysis}

A linear mixed model was used to assess the differences in change in LA and LV dimensions and function over the follow-up period between the three groups as it accounts for the correlation of repeated measurements over time within patients. The group $(1,2$, or 3$)$ and timing of echocardiogram (baseline or 1 year) were incorporated in the model as fixed variables in addition to the interaction between the group and timing of echocardiogram. Restricted maximum likelihood estimation with an unstructured covariance matrix and a random intercept model was used. The estimated marginal means and $95 \%$ confidence interval were presented. Non-Gaussian continuous variables, such as LDL, triglycerides, CRP, indexed LA volumes, mitral E-wave velocity, E/e', and E/A, were
Fig. 1 Changes in left ventricular global longitudinal strain and septal e' by group. An improvement in GLS and septal e' can be seen in Groups 2 and 3. No improvement in these parameters is noted in Group 1. Estimates from a linear mixed model. Data are presented as estimated marginal mean and $95 \%$ confidence interval. Analysis adjusted for the corresponding baseline variable, changes in $\mathrm{HbAlc}$ and weight
(A) GLS adjusted for $\mathrm{HbA} 1 \mathrm{c}$ \& weight

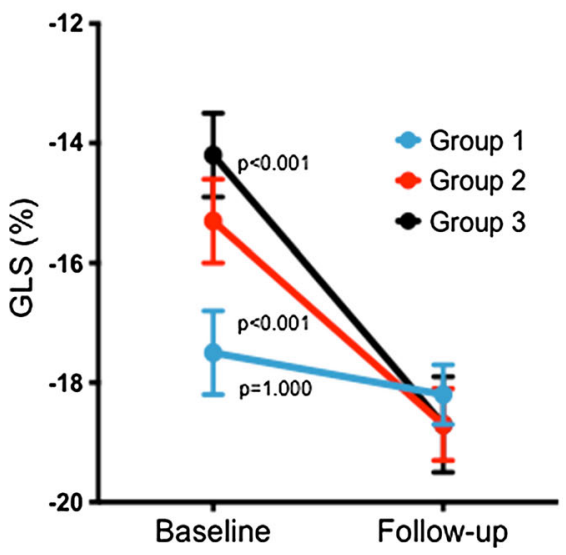

(B) Septal e' adjusted for HbA1c \& weight

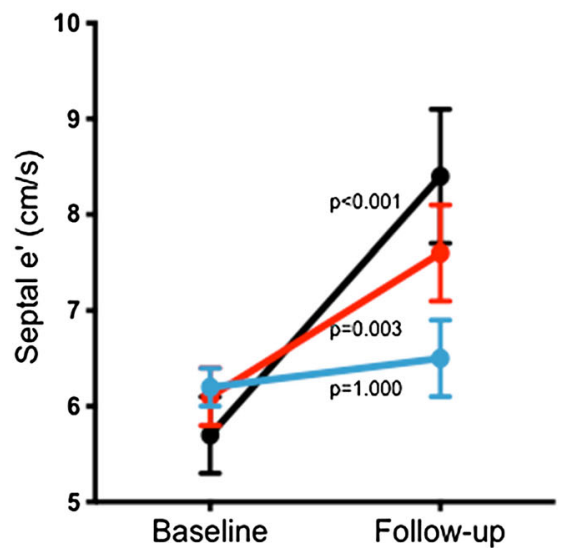


transformed as appropriate. Pairwise comparisons were performed using Bonferroni correction. The KruskalWallis test was used to compare MRC dyspnea grade between groups at baseline, and over time. A two-sided $p$ value $<0.05$ was considered significant. Statistical analyses were performed using STATA v12 (STATA Corporation, Texas).

\section{Results}

\section{Baseline clinical, metabolic, and echocardiographic characteristics}

The baseline clinical and metabolic characteristics of the three groups of patients are summarized in Table 1. The three groups of patients were comparable in all their clinical and metabolic parameters except that Group 3 patients were heaviest and had the highest body mass index (BMI). Metabolic profiles were also comparable except Group 2 had the higher total cholesterol compared with Group 1. In particular, there were no significant differences in the baseline $\mathrm{HbA} 1 \mathrm{c}$ between the three groups. Group 3 patients had the highest, though nonsignificant, baseline CRP levels. The median MRC dyspnea grade was 2 in all three groups at baseline $(p=0.798)$. Medication use at baseline is presented in Table 2 .

The baseline echocardiographic characteristics are listed in Table 3. The three groups had similar LV dimensions, wall thickness, ejection fraction, and diastolic function measured by the septal e' velocities and diastolic function grades. The LV anterior septal wall thickness was highest in Group 3, but the LV mass indices were comparable. Patients in Group 3 had the most impaired LV systolic function as measured by LV GLS and strain rate. The cIB of the LV anteroseptal wall was highest in Group 3. All measures of LA function were similar across the three groups at baseline.

\section{Follow-up clinical and echocardiographic characteristics}

Table 1 shows the follow-up clinical and metabolic characteristics of the three groups of patients. By study design, the body weights, BMI, and HbA1c of patients in Group 3 decreased significantly but that of Group 1 remained the same at 12 months. There was also an increase in HDL-C, and a marginal decrease in triglycerides in Group 3. There was a significant improvement in MRC dyspnea grade from baseline to follow-up in Group 2 (grade 2 vs. grade $1, p=0.0003$ ) and Group 3 (grade 2 vs. grade $1, p=0.001$ ), but not Group 1 (grade 2 vs. grade $2, p=0.483$ ).
Table 3 shows the follow-up echocardiographic characteristics. By 12 months, there was a reduction in $\mathrm{LV}$ anteroseptal wall thickness in Group 3 and a reduction in $\mathrm{LV}$ end systolic volume leading to an increase in LV ejection fraction in Groups 2 and 3. There was an increase in septal e' velocities (Fig. 1) and a reduction in septal E/e' ratio in Groups 2 and 3. The E/e' ratio in Group 1 actually increased. There was a reduction in the LV anteroseptal wall cIB in Group 3 only. There was a significant improvement in LV GLS and strain rate in Groups 2 and 3 with the patients in Group 3 experiencing the larger improvement (Fig. 1). The LV GLS was worst in Group 3 at baseline but was comparable between Groups 2 and 3 at follow-up.

\section{Inter- and intra-observer variability}

Left ventricular GLS measurements were repeated in ten randomly selected patients by the same observer (ML) on the same echocardiographic images, and by a second observer (DL) to determine intra-observer and inter-observer variability, respectively. The intra-observer mean differences for LV GLS were $-0.19 \pm 0.36 \%$ $(r=0.994)$. The inter-observer mean differences were $-0.33 \pm 1.02 \%(r=0.94)$.

\section{Discussion}

The present study evaluated three groups of age-, gender-, and baseline $\mathrm{HbA1c}$-matched patients with type 2 diabetes who had subclinical LV systolic and diastolic dysfunction. They received intervention by diet and exercise advice, anti-hyperglycaemic medications, and/or surgery. The resultant improvement in glycaemic control led to significant improvements in both systolic function (LV GLS and ejection fraction) and diastolic function $\left(e^{\prime}\right)$. Furthermore, weight loss in addition to improved glycaemic control (Group 3) resulted in the largest improvements in LV systolic and diastolic function, despite having worst function at baseline. Furthermore, there was a reduction in cIB in this group reflecting a decrease in myocardial interstitial fibrosis. Our study demonstrates the beneficial and additive effects of improved glycaemic control and weight loss in improving cardiac function in overweight patients with type 2 diabetes.

\section{Left ventricular systolic and diastolic function in diabetes and impact of therapeutic intervention}

The presence of LV dysfunction has been well described in patients with type 2 diabetes independent of myocardial ischaemia or hypertension [1-3]. We evaluated LV GLS 
Table 1 Baseline and follow-up clinical and metabolic characteristics in the three groups of patients

\begin{tabular}{|c|c|c|c|}
\hline Characteristic & $\begin{array}{l}\text { Group 1: no weight loss }+ \text { worse } \\
\text { glycaemic control }(n=20)\end{array}$ & $\begin{array}{l}\text { Group 2: no weight loss }+ \text { improved } \\
\text { glycaemic control }(n=20)\end{array}$ & $\begin{array}{l}\text { Group 3: weight loss }+ \text { improved } \\
\text { glycaemic control }(n=10)\end{array}$ \\
\hline \multicolumn{4}{|c|}{ Body mass index $\left(\mathrm{kg} / \mathrm{m}^{2}\right)$} \\
\hline Baseline & $34.4(31.2-37.5)$ & $31.5(28.3-34.7)$ & $44.3(39.8-48.7)^{\S \dagger}$ \\
\hline Follow-up & $35.7(32.5-38.8)$ & $32.5(29.4-35.7)^{*}$ & $34.5(30.0-40.0)^{*}$ \\
\hline \multicolumn{4}{|l|}{ Weight $(\mathrm{kg})$} \\
\hline Baseline & $92.1(82.1-102.0)$ & $81.3(71.3-91.2)$ & $123.6(109.5-137.7)^{\S \dagger}$ \\
\hline Follow-up & $94.2(85.1-103.3)^{*}$ & $84.3(75.2-93.4)^{*}$ & $95.7(82.8-108.5)^{*}$ \\
\hline \multicolumn{4}{|c|}{ Waist circumference $(\mathrm{cm})$} \\
\hline Baseline & $109(102,115)$ & $103(96,109)^{\S}$ & $128(119,137)^{\dagger}$ \\
\hline Follow-up & $111(104,117)$ & $105(99,111)$ & $114(106,122)^{*}$ \\
\hline \multicolumn{4}{|c|}{ Waist-to-hip ratio } \\
\hline Baseline & $0.94(0.91-0.98)$ & $0.95(0.91-0.99)$ & $0.94(0.89-0.99)$ \\
\hline Follow-up & $0.94(0.91-0.96)$ & $0.96(0.93-0.99)$ & $0.96(0.92-1.00)$ \\
\hline \multicolumn{4}{|c|}{ Systolic blood pressure (mmHg) } \\
\hline Baseline & $137(129-144)$ & $133(125-140)$ & $128(117-138)$ \\
\hline Follow-up & $134(128-140)$ & $129(123-135)$ & $131.4(123-140)$ \\
\hline \multicolumn{4}{|c|}{ Diastolic blood pressure $(\mathrm{mmHg})$} \\
\hline Baseline & $78(73-82)$ & $73(68-78)$ & $74(68-81)$ \\
\hline Follow-up & $81(77-86)$ & $77(72-81)$ & $79(72-85)$ \\
\hline \multicolumn{4}{|c|}{ HbA1c, NGSP (\%) IFCC (mmol/mol) } \\
\hline \multirow[t]{2}{*}{ Baseline } & $9.4(8.6-10.2)$ & $9.9(9.1-10.7)$ & $9.5(8.4-10.6)$ \\
\hline & $79(70-88)$ & $85(76-93)$ & $80(68-92)$ \\
\hline \multirow[t]{2}{*}{ Follow-up } & $9.5(8.7-10.3)$ & $7.3(6.5-8.1)^{* \dagger}$ & $6.7(5.5-7.1)^{* \dagger}$ \\
\hline & $80(72-89)$ & $56(48-65)$ & $50(37-54)$ \\
\hline \multicolumn{4}{|c|}{ Total cholesterol (mg/dL) } \\
\hline Baseline & $5.2(4.7-5.7)$ & $4.1(3.5-4.6)^{\dagger}$ & $5.0(4.3-5.8)$ \\
\hline Follow-up & $4.8(4.3-5.4)$ & $3.8(3.2-4.3)^{\dagger}$ & $4.6(3.9-5.4)$ \\
\hline \multicolumn{4}{|c|}{ LDL cholesterol (mg/dL) } \\
\hline Baseline & $2.7(2.2-3.3)$ & $1.8(1.5-2.1)^{\dagger}$ & $2.6(2.0-3.4)$ \\
\hline Follow-up & $2.3(1.8-2.1)$ & $1.8(1.4-2.2)$ & $2.5(1.8-3.3)$ \\
\hline \multicolumn{4}{|c|}{ HDL cholesterol (mg/dL) } \\
\hline Baseline & $1.2(1.1-1.4)$ & $1.3(1.2-1.4)$ & $1.09(0.9-1.3)$ \\
\hline Follow-up & $1.2(1.1-1.3)$ & $1.2(1.1-1.3)$ & $1.2(1.1-1.4)^{*}$ \\
\hline \multicolumn{4}{|c|}{ Triglycerides (mg/dL) } \\
\hline Baseline & $1.7(1.4-2.2)$ & $1.3(1.1-1.6)$ & $2.2(1.5-3.2)$ \\
\hline Follow-up & $1.7(1.4-2.2)$ & $1.2(1.0-1.5)$ & $1.4(1.1-1.9)$ \\
\hline \multicolumn{4}{|c|}{$\mathrm{eGFR}\left(\mathrm{mL} / \mathrm{min} / 1.73 \mathrm{~m}^{2}\right)$} \\
\hline Baseline & 91 (83-99) & $92(84-99)$ & $89(78-100)$ \\
\hline Follow-up & $101(93-110)$ & $84(75-92)$ & $96(84-108)$ \\
\hline \multicolumn{4}{|c|}{ C-reactive protein $(\mathrm{mg} / \mathrm{L})$} \\
\hline Baseline & $3.6(2.2-5.9)$ & $3.0(1.8-5.1)$ & $10.2(5.2-19.8)$ \\
\hline Follow-up & $2.8(1.8-4.4)$ & $2.7(1.7-4.4)$ & $4.4(2.3-8.4)$ \\
\hline
\end{tabular}

Estimates from a linear mixed model. Data are presented as estimated marginal means and $95 \%$ confidence interval NGSP National glycohaemoglobin standardization programme

Within groups: $* p<0.05$ for 1 -year follow-up versus baseline Between groups: ${ }^{\S} p<0.001$ versus Group $2 ;{ }^{\dagger} p<0.05$ versus Group 1 
Table 2 Baseline medications in the three groups of patients

\begin{tabular}{|c|c|c|c|}
\hline Medication & $\begin{array}{l}\text { Group 1: no weight } \\
\text { loss }+ \text { worse glycaemic } \\
\text { control }(n=20)\end{array}$ & $\begin{array}{l}\text { Group 2: no weight } \\
\text { loss }+ \text { improved glycaemic } \\
\text { control }(n=20)\end{array}$ & $\begin{array}{l}\text { Group 3: weight } \\
\text { loss }+ \text { improved glycaemic } \\
\text { control }(n=10)\end{array}$ \\
\hline Aspirin or clopidogrel, $n(\%)$ & $10(25 \%)$ & $16(40 \%)$ & $4(20 \%)$ \\
\hline $\begin{array}{l}\text { Angiotensin converting enzyme inhibitor } \\
\text { or angiotensin-II receptor blocker, } \\
n(\%)\end{array}$ & $32(80 \%)$ & $26(65 \%)$ & $16(80 \%)$ \\
\hline Calcium channel blocker, $n(\%)$ & $0(0 \%)$ & $6(15 \%)$ & $6(30 \%)$ \\
\hline Beta-blocker, $n(\%)$ & $2(5 \%)$ & $4(10 \%)$ & $0(0 \%)$ \\
\hline Diuretic, $n(\%)$ & $6(15 \%)$ & $2(5 \%)$ & $4(20 \%)$ \\
\hline Spironolactone, $n(\%)$ & $0(0 \%)$ & $2(5 \%)$ & $0(0 \%)$ \\
\hline Statin, $n(\%)$ & $28(70 \%)$ & $26(65 \%)$ & $10(50 \%)$ \\
\hline Sulfonylurea, $n(\%)$ & $6(15 \%)$ & $20(50 \%)$ & $6(30 \%)$ \\
\hline Biguanide, $n(\%)$ & $38(95 \%)$ & $32(80 \%)$ & $18(90 \%)$ \\
\hline Di-peptidyl peptidase-4 inhibitor, $n(\%)$ & $10(26 \%)$ & $8(20 \%)$ & $4(20 \%)$ \\
\hline Insulin, $n(\%)$ & $20(50 \%)$ & $16(40 \%)$ & $10(50 \%)$ \\
\hline
\end{tabular}

and e' velocities in our patients as measures of LV systolic and diastolic function, respectively. These measures have proven advantages over $\mathrm{LV}$ ejection fraction and mitral $\mathrm{E}$ and $\mathrm{A}$ velocities as measures of $\mathrm{LV}$ systolic and diastolic function, respectively. In addition, both LV GLS and e' velocities have incremental prognostic value over a wide range of cardiovascular diseases [22, 28].

The underlying pathophysiologic mechanisms of diabetic cardiomyopathy are multifactorial and hyperglycaemia plays a central role [6] Furthermore, patients with type 2 diabetes are often obese and obesity per se has been linked to LV dysfunction [29].

There is increasing evidence to suggest a link between glycaemic control and LV function in diabetes. Studies have suggested poor glycaemic control was associated with LV diastolic dysfunction, manifest as either lower e' velocities or raised LV filling pressure; and/or more impaired LV systolic function with lower systolic strain $[2,8,9]$. Furthermore, we have recently demonstrated that improving glycaemic control in such patients resulted in improvement in LV systolic and diastolic function [30]. The largest improvements in the aforementioned study were seen in patients with the largest reduction in $\mathrm{HbAlc}$ levels, and in those with the lowest HbA1c levels at the end of the study. In contrast, patients who had worsened glycaemic control experienced further deterioration of $\mathrm{LV}$ systolic function. However, studies examining the additive effects of weight loss and improved glycaemic control on LV function changes have been lacking.

Weight loss, however achieved, has been shown to result in improved LV systolic and diastolic function [31]. In a study of 261 patients with $\mathrm{BMI} \geq 30 \mathrm{~kg} / \mathrm{m}^{2}$ who undertook a behavioural intervention programme including dietary restriction and exercise training, independent predictors of improvement in LV function were weight reduction, improvement in insulin resistance and absence of diabetes [32]. There was no significant reduction in HbA1c levels with intervention in either the adherent group or in the non-adherent group; therefore, the effects of improved glycaemic control on LV function was not examined. Caloric restriction in obese patients with type 2 diabetes led to improved LV diastolic function [33]. The severely obese patients have greater inflammatory burden suggested by the significantly higher C-reactive protein levels seen in patients in Group 3. While bariatric surgery has proven benefits in weight reduction in obese patients which leads to improvement in LV systolic and diastolic function [34, 35], it is a different treatment approach to dieting and exercise with additional impact on the neurohormonal axis. Patients who have undergone sleeve gastrectomy have been found to have reduced ghrelin levels, while the hindgut theory proposes that rapid delivery of undigested nutrients to the hindgut following bariatric surgery up-regulates production of glucagon-like peptide 1 and peptide-YY [36, 37]. How these neuro-hormonal changes contribute to improvement in diabetic cardiomyopathy is unclear. In a study of severely obese patients, beneficial effects of weight loss with bariatric surgery on ECG abnormalities were seen more often in those who lost weight and achieved normotension [38]. This supports the importance of targeting multiple co-morbidities in these patients to achieve desirable therapeutic goals.

Our study underlines the importance of both weight loss and improving glycaemic control for the improvement of 
Table 3 Baseline and follow-up echocardiographic characteristics in the three groups of patients

\begin{tabular}{|c|c|c|c|}
\hline Characteristic & $\begin{array}{l}\text { Group 1: no weight loss }+ \text { worse } \\
\text { glycaemic control }(n=20)\end{array}$ & $\begin{array}{l}\text { Group 2: no weight loss }+ \text { improved } \\
\text { glycaemic control }(n=20)\end{array}$ & $\begin{array}{l}\text { Group 3: weight loss }+ \text { improved } \\
\text { glycaemic control }(n=10)\end{array}$ \\
\hline \multicolumn{4}{|c|}{ LV mass index $\left(\mathrm{g} / \mathrm{m}^{2}\right)$} \\
\hline Baseline & $78.9(68.6-89.3)$ & $93.5(83.1-103.9)$ & $90.1(75.4-104.8)$ \\
\hline Follow-up & $83.3(75.5-91.0)$ & $89.2(81.4-97.0)$ & $75.6(64.6-86.5)$ \\
\hline \multicolumn{4}{|c|}{ LV end diastolic volume (mL) } \\
\hline Baseline & $67(58-80)$ & $66(54-78)$ & $89(72-106)$ \\
\hline Follow-up & $71(60-82)$ & $64(53-76)$ & $91(75-107)$ \\
\hline \multicolumn{4}{|c|}{ LV end systolic volume (mL) } \\
\hline Baseline & $24(18-31)$ & $27(20-34)$ & $36(26-45)$ \\
\hline Follow-up & $23(18-27)$ & $20(15-24)$ & $29(22-35)$ \\
\hline \multicolumn{4}{|l|}{$\operatorname{LVEF}(\%)$} \\
\hline Baseline & $65(62-69)$ & $61(58-65)$ & $60(54-65)$ \\
\hline Follow-up & $69(66-72)$ & $70(66-73)^{*}$ & $69(64-73)^{*}$ \\
\hline \multicolumn{4}{|l|}{$\mathrm{E}(\mathrm{cm} / \mathrm{s})$} \\
\hline Baseline & $74(67-83)$ & $67(61-75)$ & $70(61-82)$ \\
\hline Follow-up & $80(72-88)$ & $75(68-82)$ & $73(64-83)$ \\
\hline \multicolumn{4}{|l|}{$\mathrm{A}(\mathrm{cm} / \mathrm{s})$} \\
\hline Baseline & $87(78-96)$ & $72(63-81)$ & $82(70-95)$ \\
\hline Follow-up & $88(80-96)$ & $73(66-81)$ & $80(69-91)$ \\
\hline \multicolumn{4}{|l|}{$\mathrm{E} / \mathrm{A}$} \\
\hline Baseline & $1.06(0.98-1.13)$ & $1.03(0.95-1.10)$ & $1.07(0.96-1.18)$ \\
\hline Follow-up & $1.06(0.99-1.12)$ & $1.00(0.93-1.07)$ & $1.07(0.97-1.17)$ \\
\hline \multicolumn{4}{|c|}{ Septal s' (cm/s) } \\
\hline Baseline & $7.0(6.4-7.6)$ & $6.5(5.9-8.1)$ & $6.1(5.3-6.9)$ \\
\hline Follow-up & $6.8(6.3-7.3)$ & $6.5(6.0-7.0)$ & $6.5(5.7-7.3)$ \\
\hline \multicolumn{4}{|c|}{ Septal e' $(\mathrm{cm} / \mathrm{s})$} \\
\hline Baseline & $6.3(5.8-6.7)$ & $6.1(5.6-6.6)$ & $5.9(5.2-6.6)$ \\
\hline Follow-up & $6.6(5.7-7.4)$ & $7.5(6.6-8.3)^{*}$ & $8.2(7.0-9.4)^{*}$ \\
\hline \multicolumn{4}{|c|}{ Septal a' (cm/s) } \\
\hline Baseline & $9.6(8.5-10.6)$ & $8.8(7.7-9.8)$ & $8.8(7.3-10.3)$ \\
\hline Follow-up & $9.2(8.3-10.1)$ & $8.1(7.2-9.0)$ & $8.2(7.0-9.4)$ \\
\hline \multicolumn{4}{|l|}{ Septal E/e' } \\
\hline Baseline & $11.9(10.7-13.5)$ & $11.1(10-12.5)$ & $11.9(10.2-14.2)$ \\
\hline Follow-up & $12.3(10.7-14.5)$ & $10.2(9.1-11.6)$ & $9.0(7.8-10.7)^{*}$ \\
\hline \multicolumn{4}{|c|}{ LA dimension $(\mathrm{mm})$} \\
\hline Baseline & $35(33,38)$ & $35(33,38)$ & $39(46,42)$ \\
\hline Follow-up & $36(34,38)$ & $33(31,35)$ & $33(30,36)^{*}$ \\
\hline \multicolumn{4}{|c|}{ LA maximum volume indexed $\left(\mathrm{mL} / \mathrm{m}^{2}\right)$} \\
\hline Baseline & $26(24-28)$ & $28(26-32)$ & $28(24-32)$ \\
\hline Follow-up & $27(24-31)$ & $28(25-31)$ & $30(25-36)$ \\
\hline \multicolumn{4}{|c|}{ LA active emptying volume indexed $\left(\mathrm{mL} / \mathrm{m}^{2}\right)$} \\
\hline Baseline & $10(9-12)$ & $10(8-11)$ & $9(7-11)$ \\
\hline Follow-up & $10(8-11)$ & $10(8-11)$ & $12(10-14)$ \\
\hline \multicolumn{4}{|c|}{ LA passive emptying volume indexed $\left(\mathrm{mL} / \mathrm{m}^{2}\right)$} \\
\hline Baseline & $9(8-11)$ & $11(9-13)$ & $13(11-15)$ \\
\hline Follow-up & $11(9-14)$ & $11(9-13)$ & $11(8-14)$ \\
\hline \multicolumn{4}{|c|}{ Anteroseptal wall cIB (dB) } \\
\hline Baseline & $-14.1(-16.6$ to 11.6$)$ & $-10.6(-13.1$ to 8.1$)$ & $-6.0(-9.6$ to 2.5$) \dagger$ \\
\hline
\end{tabular}


Table 3 continued

\begin{tabular}{llll}
\hline $\begin{array}{l}\text { Characteristic } \\
\text { glycaemic control }(n=20)\end{array}$ & $\begin{array}{l}\text { Group 1: no weight loss }+ \text { worse } \\
\text { glycaemic control }(n=20)\end{array}$ & $\begin{array}{l}\text { Group 3: weight loss }+ \text { improved } \\
\text { glycaemic control }(n=10)\end{array}$ \\
\hline Follow-up & $-14.1(-16.4$ to 11.8$)$ & $-12.5(-14.8$ to 10.2$)$ & $-13.1(-16.4 \text { to } 9.8)^{*}$ \\
Posterior wall cIB (dB) & $-16.5(-19.0$ to 14.1$)$ & $-15.3(-17.4$ to 13.2$)$ & $-11.7(-15.2$ to 8.3$)$ \\
Baseline & $-16.6(-18.8$ to 14.5$)$ & & $-13.9(-16.9 \text { to } 10.9)^{*}$ \\
Follow-up & $-17.3(-18.6$ to 16.0$)$ & $-15.3(-16.6$ to 14.0$)$ & $-13.0(-14.8$ to 11.2$) \dagger$ \\
LV global longitudinal systolic strain $(\%)$ & & $-19.3(-18.9 \text { to } 17.8)^{*}$ \\
Baseline & $-17.9(-19.0$ to 16.8$)$ & $-0.82(-0.89$ to 0.74$) \dagger$ & $-0.77(-0.87$ to 0.66$) \dagger$ \\
Follow-up & $-0.99(-1.06$ to 0.91$)$ & $-1.03(-1.1 \text { to } 0.96)^{*}$ & $-0.99(-1.1 \text { to } 0.89)^{*}$ \\
LV global longitudinal systolic strain rate $(1 / \mathrm{s})$ &
\end{tabular}

Estimates from a linear mixed model. Data are presented as estimated marginal means and $95 \%$ confidence interval

Within groups: $* p<0.05$ for 1-year follow-up versus baseline

Between groups: ${ }^{\dagger} p<0.05$ versus Group 1

cardiac function in obese patients with type 2 diabetes. In looking after subjects with type 2 diabetes, clinicians are often faced with the task of managing their obesity as an adjunct to improve their glycaemic control. Many therapies for diabetes such as insulin and thiazolidinediones may improve glycaemic control, but these agents can increase the weight of patients. Poor glycaemic control and obesity are both associated with worsening of LV function, and targeting both parameters may have important and independent effects in preventing the development of diabetic cardiomyopathy. Given the current obesity epidemic and prevalence of obesity and diabetic cardiomyopathy, these results have important implications for preventing obesity and diabetes-related morbidity and mortality.

\section{Limitations}

Our study was not a randomized trial. Such a study would have been unethical. Given that the goal of our study was to better understand the contributions of weight loss and glycaemic improvement towards modulating LV function, we used a group of patients with no weight loss and no improvement in glycaemic control as a reference category, and these patients may have been inherently different from subjects in the other two groups. We did not have a group of patients who achieved weight loss without any reduction in $\mathrm{HbA} 1 \mathrm{c}$ levels to examine the independent contribution of weight loss alone without improved glycaemic control on LV function. However, as the study by Kosmala et al. has shown [32], improvement in LV function with weight loss alone (their patients did not have significant reduction in HbA1c with behavioural intervention) was less frequently observed in patients with diabetes. We did not evaluate changes in insulin resistance in our patients.
Weight loss in our Group 3 patients was achieved with sleeve gastrectomy. The addition of a further group of patients who were able to both improve glycaemic control and lose weight by non-surgical means, and who are matched to group 1 and 2 for age, gender, BMI, and baseline $\mathrm{HbA1c}$ would be ideal. Unfortunately, we do not have such a group of patients in this study. This, together with the high non-adherence rate in the Kosmala study, highlight the significant challenges in achieving significant weight loss in patients with type 2 diabetes and obesity, despite an intensive and supervised multidisciplinary approach. Finally, for patients who are only overweight or only mildly obese, we cannot be certain whether weight loss by diet and exercise alone and better glycaemic control confer additive benefits.

\section{Conclusions}

In overweight patients with type 2 diabetes, weight loss and improved glycaemic control had additive beneficial effects on improving LV systolic and diastolic function.

Acknowledgments M.L. received funding from an NHRMC postgraduate research scholarship and Pfizer Investigator Initiated Research Grant. None of the other authors received funding.

\section{Compliance with ethical standards}

Conflict of interest The authors have no conflicts of interest to declare.

Statement of human rights All procedures followed were in accordance with the ethical standards of the responsible committee on human experimentation (institutional and national) and with the Helsinki Declaration of 1975 , as revised in 2008. 
Informed consent All subjects had normal resting electrocardiogram and provided written informed consent.

Open Access This article is distributed under the terms of the Creative Commons Attribution 4.0 International License (http://crea tivecommons.org/licenses/by/4.0/), which permits unrestricted use, distribution, and reproduction in any medium, provided you give appropriate credit to the original author(s) and the source, provide a link to the Creative Commons license, and indicate if changes were made.

\section{References}

1. Devereux RB, Roman MJ, Paranicas M et al (2000) Impact of diabetes on cardiac structure and function: the strong heart study. Circulation 101(19):2271-2276

2. Fang ZY, Schull-Meade R, Downey M, Prins J, Marwick TH (2005) Determinants of subclinical diabetic heart disease. Diabetologia 48(2):394-402

3. Ng AC, Delgado V, Bertini M et al (2009) Findings from left ventricular strain and strain rate imaging in asymptomatic patients with type 2 diabetes mellitus. Am $\mathrm{J}$ Cardiol 104(10):1398-1401

4. Tadic M, Cuspidi C, Vukomanovic V et al (2016) The influence of type 2 diabetes and arterial hypertension on right ventricular layer-specific mechanics. Acta Diabetol. doi:10.1007/s00592016-0874-9

5. Habek JC, Lakusic N, Kruzliak P, Sikic J, Mahovic D, Vrbanic L (2014) Left ventricular diastolic function in diabetes mellitus type 2 patients: correlation with heart rate and its variability. Acta Diabetol 51(6):999-1005. doi:10.1007/s00592-014-0658-z

6. Aneja A, Tang W, Bansilal S, Garcia MJ, Farkouh ME (2008) Diabetic cardiomyopathy: insights into pathogenesis, diagnostic challenges, and therapeutic options. Am J Med 121(9):748-757

7. Salerno A, Fragasso G, Esposito A et al (2015) Effects of shortterm manipulation of serum FFA concentrations on left ventricular energy metabolism and function in patients with heart failure: no association with circulating bio-markers of inflammation. Acta Diabetol 52(4):753-761. doi:10.1007/s00592-014-0695-7

8. Vinereanu D, Nicolaides E, Tweddel AC et al (2003) Subclinical left ventricular dysfunction in asymptomatic patients with type II diabetes mellitus, related to serum lipids and glycated haemoglobin. Clin Sci (Lond) 105(5):591-599. doi:10.1042/ CS20030168

9. Liu JE, Palmieri V, Roman MJ et al (2001) The impact of diabetes on left ventricular filling pattern in normotensive and hypertensive adults: the Strong Heart Study. J Am Coll Cardiol 37(7):1943-1949

10. Poirier P, Bogaty P, Garneau C, Marois L, Dumesnil JG (2001) Diastolic dysfunction in normotensive men with well-controlled type 2 diabetes: importance of maneuvers in echocardiographic screening for preclinical diabetic cardiomyopathy. Diabet Care 24(1):5-10

11. Tarumi N, Iwasaka T, Takahashi $\mathrm{N}$ et al (1993) Left ventricular diastolic filling properties in diabetic patients during isometric exercise. Cardiology 83(5-6):316-323

12. Gough S, Smyllie J, Barker M, Berkin K, Rice P, Grant P (1995) Diastolic dysfunction is not related to changes in glycaemic control over 6 months in type 2 (non-insulin-dependent) diabetes mellitus. Acta Diabetol 32(2):110-115

13. Beljic T, Miric M (1994) Improved metabolic control does not reverse left ventricular filling abnormalities in newly diagnosed non-insulin-dependent diabetes patients. Acta Diabetol 31(3):147-150
14. Lo S, Leslie R, Sutton M (1995) Effects of type 1 diabetes mellitus on cardiac function: a study of monozygotic twins. $\mathrm{Br}$ Heart J 73(5):450-455

15. Von Bibra H, Hansen A, Dounis V, Bystedt T, Malmberg K, Rydén L (2004) Augmented metabolic control improves myocardial diastolic function and perfusion in patients with noninsulin dependent diabetes. Heart 90(12):1483-1484

16. Jarnert C, Landstedt-Hallin L, Malmberg K et al (2009) A randomized trial of the impact of strict glycaemic control on myocardial diastolic function and perfusion reserve: a report from the DADD (diabetes mellitus and diastolic dysfunction) study. Eur J Heart Fail 11(1):39-47

17. Sutton MSJ, Rendell M, Dandona P (2002) A comparison of the effects of rosiglitazone and glyburide on cardiovascular function and glycemic control in patients with type 2 diabetes. Diabet Care 25(11):2058-2064

18. Thrainsdottir I, Malmberg K, Olsson A, Gutniak M, Rydén L (2004) Initial experience with GLP-1 treatment on metabolic control and myocardial function in patients with type 2 diabetes mellitus and heart failure. Diabet Vasc Dis Res 1(1):40-43

19. Holland DJ, Marwick TH, Haluska BA (2015) Subclinical LV dysfunction and 10-year outcomes in type 2 diabetes mellitus. Heart 101(13):1061-1066. doi:10.1136/heartjnl-2014-307391

20. Fang ZY, Yuda S, Anderson V, Short L, Case C, Marwick TH (2003) Echocardiographic detection of early diabetic myocardial disease. J Am Coll Cardiol 41(4):611-617

21. Ng AC, Sitges M, Pham PN et al (2009) Incremental value of 2-dimensional speckle tracking strain imaging to wall motion analysis for detection of coronary artery disease in patients undergoing dobutamine stress echocardiography. Am Heart J 158(5):836-844. doi:10.1016/j.ahj.2009.09.010

22. Wang M, Yip GW, Wang AY et al (2003) Peak early diastolic mitral annulus velocity by tissue Doppler imaging adds independent and incremental prognostic value. J Am Coll Cardiol 41(5):820-826

23. Picano E, Pelosi G, Marzilli M (1990) In vivo quantitative ultrasonic evaluation of myocardial fibrosis in humans. Circulation 81(1):58-64

24. Lythall DA, Bishop J, Greenbaum RA et al (1993) Relationship between myocardial collagen and echo amplitude in non-fibrotic hearts. Eur Heart J 14(3):344-350

25. Rider OJ, Francis JM, Ali MK et al (2009) Beneficial cardiovascular effects of bariatric surgical and dietary weight loss in obesity. J Am Coll Cardiol 54(8):718-726. doi:10.1016/j.jacc.2009.02.086

26. Stenton C (2008) The MRC breathlessness scale. Occup Med 58(3):226-227. doi:10.1093/occmed/kqm162

27. Levey AS, Stevens LA, Schmid CH et al (2009) A new equation to estimate glomerular filtration rate. Ann Intern Med 150(9):604-612

28. Kalam K, Otahal P, Marwick TH (2014) Prognostic implications of global LV dysfunction: a systematic review and meta-analysis of global longitudinal strain and ejection fraction. Heart 100(21):1673-1680. doi:10.1136/heartjnl-2014-305538

29. Alpert MA (2001) Obesity cardiomyopathy: pathophysiology and evolution of the clinical syndrome. Am J Med Sci 321(4):225-236

30. Leung M, Wong VW, Hudson M, Leung DY (2016) Impact of improved glycemic control on cardiac function in type 2 diabetes mellitus. Circ Cardiovasc Imag 9(3):e003643

31. Cuspidi C, Rescaldani M, Tadic M, Sala C, Grassi G (2013) Effects of bariatric surgery on cardiac structure and function: a systematic review and meta-analysis. Am J Hypertens 27(2):146-156

32. Kosmala W, O'Moore-Sullivan T, Plaksej R, Przewlocka-Kosmala M, Marwick TH (2009) Improvement of left ventricular function by lifestyle intervention in obesity: contributions of weight loss and reduced insulin resistance. Diabetologia 52(11):2306-2316. doi:10.1007/s00125-009-1507-4 
33. Hammer S, Snel M, Lamb HJ et al (2008) Prolonged caloric restriction in obese patients with type 2 diabetes mellitus decreases myocardial triglyceride content and improves myocardial function. J Am Coll Cardiol 52(12):1006-1012

34. Leung M, Xie M, Durmush E, Leung DY, Wong VW (2016) Weight loss with sleeve gastrectomy in obese type 2 diabetes mellitus: impact on cardiac function. Obes Surg 26(2):321-326. doi:10.1007/s11695-015-1748-x

35. Ashrafian H, le Roux CW, Darzi A, Athanasiou T (2008) Effects of bariatric surgery on cardiovascular function. Circulation 118(20):2091-2102

36. Karamanakos SN, Vagenas K, Kalfarentzos F, Alexandrides TK (2008) Weight loss, appetite suppression, and changes in fasting and postprandial ghrelin and peptide-YY levels after Roux-en-Y gastric bypass and sleeve gastrectomy: a prospective, double blind study. Ann Surg 247(3):401-407. doi:10.1097/SLA. 0b013e318156f012

37. Garibay D, McGavigan AK, Lee SA, Ficorilli JV, Cox AL, Michael MD, Sloop KW, Cummings BP (2016) Beta-cell glucagon-like peptide-1 receptor contributes to improved glucose tolerance after vertical sleeve gastrectomy. Endocrinology. doi:10.1210/en.2016-1302

38. Pontiroli A, Pizzocri P, Saibene A, Girola A, Koprivec D, Fragasso G (2004) Left ventricular hypertrophy and QT interval in obesity and in hypertension: effects of weight loss and of normalisation of blood pressure. Int J Obes 28(9):1118-1123 